\title{
Reproductive Medicine International
}

RESEARCH ARTICLE

\section{Effectiveness of Homoeopathic Treatment in Female Infertility}

\author{
Anita Lobo ${ }^{1 *}$, Prema D'cunha' and Blany Lobo ${ }^{3}$ \\ ${ }^{1}$ Department of Repertory, Fr Muller Homoeopathic Medical College, India \\ ${ }^{2}$ Department of Obstetrics and Gynaecology, Fr Muller Medical College, India \\ ${ }^{3}$ Department of Pharmacy, Fr Muller Homoeopathic Medical College, India
}

*Corresponding author: Anita Lobo, Department of Repertory, Fr Muller Homoeopathic Medical College, Deralakatte, Mangaluru, Karnataka-575018, India

\begin{abstract}
Background: Infertility is the inability of a couple to achieve conception after one year of unprotected coitus. Today almost one in six couples face difficulty in conceiving (1). The rise in female infertility and the use of alternative systems in sharing the global burden of treating infertility has remarkably increased. Homoeopathy is often effective in curing infertility where conventional medicine either fails or is expensive or requires operative procedures and hormonal therapy with their added complication and side effects.
\end{abstract}

Objective: To evaluate the efficacy of homoeopathic constitutional similimum in the management of female infertility.

Materials and methods: 40 cases of infertile women presenting at the hospital opd and fulfilling the inclusion and exclusion criteria were selected by purposive sampling method for a period of one and a half year during which the constitutional remedy based on homoeopathic principles and practice was administered in suitable potencies. The outcome measures of positive pregnancy i.e. Urine Pregnancy Test (Earlie Icon) and USG of pelvis were chosen to evaluate the research results.

Result: Homoeopathic constitutional remedies were successful in treating 27 out of 40 cases testing positive for Urine Pregnancy Test (Earlie Icon) and USG of pelvis. Data from the sample subjected to McNemar's test to determine the significance of the effectiveness of Homoeopathic treatment found ' $p$ ' value in PCOD and Chronic PID to be 0.001 and 0.002 respectively, that were highly significant. ' $p$ ' value in Endometriosis was 0.206 , not significant. The effectiveness of treatment by the rate of conception in these infertile females was overall $(67.5 \%)$ and the ' $P$ ' value was 0.002 that is significant as per statistical value.

Conclusion: Homoeopathy is effective in therapeutic management of female infertility. The well indicated constitutional remedy given on the basis of symptoms' similarity has helped the infertile patients to conceive.

\section{Keywords}

Female Infertility, PCOD, Chronic PID, Endometriosis, Constitutional remedies

\section{Introduction}

The incidence of female infertility is rapidly increasing among the Indian population which is also a reflection of what is happening all over the world. Today almost one in six couples face difficulty in conceiving (ref). Infertility is the inability of a couple to achieve conception after one year of unprotected coitus [1]. Around 36 to $44 \%$ Infertility in women is due to ovulatory dysfunction [2]. Chronic P.I.D.is also seen in reproductive age group and is an important cause of female infertility [3]. Endometriosis is one of the main illnesses affecting women during their fertile age. In infertility apart from surgical and medical treatment, like hormonal therapies etc., [4], Homoeopathy, is emerging as one such treatment with a definite role. The role of homoeopathy in treating infertility successfully is invaluable and often taken for granted thus creating a lacunae for genuine evidence based research findings. There is a global need for carrying out evidence based research, to avoid the unnecessary ill-effects, side-effects of antibiotics, hormonal therapy and complicated surgeries and to highlight the effectiveness of homoeopathy in the treatment of infertility. In a third world country like India, often the infertile females cannot afford surgery or expensive medication and they are always targeted and blamed for being infertile, causing immense psychological and mental torture, affecting their health and social status

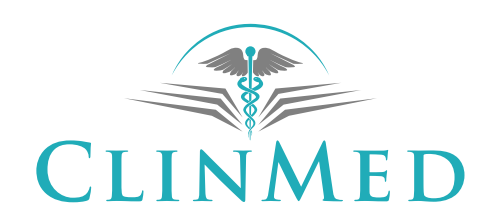

Citation: Lobo A, D'cunha P, Lobo B (2018) Effectiveness of Homoeopathic Treatment in Female Infertility. Reprod Med Int 1:008.

Accepted: December 17, 2018; Published: December 19, 2018

Copyright: (C) 2018 Lobo A, et al. This is an open-access article distributed under the terms of the Creative Commons Attribution License, which permits unrestricted use, distribution, and reproduction INTER NATIONAL LIBRARY in any medium, provided the original author and source are credited. 
(ref).., Homoeopathic medicines are simple, safe, cost effective result oriented and being holistic can address these factors also by treating the underlying causes and preventing the ill effects of conventional medicine. This study has been carried out with the objective of assessing and evaluating the efficacy of Homoeopathic medicines (intervention) in treating infertile females to successful conception.

\section{Objectives}

To assess and evaluate the efficacy of homoeopathic constitutional similimum in the management of female infertility.

\section{Materials and Methods}

Approval of the Institutional Ethics Committee of Father Muller Charitable Institutions was obtained before the initiation of the project. Infertile patients attending the obstetric and gynaecology opd of $\mathrm{Fr}$ Muller Homoeopathic Hospital were selected and their approval for the research was taken after obtaining their signs on the consent forms.

\section{Study Design}

During a period of one and half year approximately 100 patients were enrolled randomly and investigations like Ultrasonography of abdomen and pelvis, Hysterosalpingography and Diagnostic laparoscopy were carried out whenever required to ensure enrollment of a minimum of 40 patients for completion of the trial.

\section{Inclusion Criteria}

- Only female infertile women

- Age group of $18-40$ years

- Cases of PCOS, Endometriosis and Chronic PID

- Primary and Secondary Infertility.

\section{Exclusion Criteria}

- All other causes such as unknown infertility, congenital defects.

- Women whose husband's semen analysis is abnormal.

Data collection instruments: Standardized case records of OPD

Setting: OPD of Homeopathic Medical College

Population: Women visiting the obstetric and gynecology OPD for infertility treatment

Sample: 40 Women diagnosed with infertility fulfilling the inclusion and exclusion criteria
Sampling technique: Purposive sampling

Feasibility: The study is feasible in terms of availability of patients at our OPD settings

Duration of study: Total of 3 years.

Patients were analyzed using investigations like UItrasonography of abdomen and pelvis, Hysterosalpingography and Diagnostic laparoscopy as and when required before and after treatment. Homoeopathic remedies were procured from a licensed pharmaceutical company which are prepared according to the standards of the Homoeopathic Pharmacopoeia of India. Case-taking was done by Interns and post-graduates under the supervision of the Principal Investigator. The remedy was chosen according to the principles and practices of homoeopathy and given on the basis of constitutional totality after detailed case taking recording interpretation and evaluation of symptoms and when required repertorisation. The potency of remedy selected based on individual susceptibility was 200, 1 packet of powder, weekly for 2 months followed by $1 \mathrm{M}, 1$ packet of powder once in 15 days for 2 months. Counselling was done and advice on frequency of intercourse was given. When the patients menses was delayed, urine pregnancy test was advised.

Criteria for deciding the effectiveness of Homoeopathic remedies in female infertility was based on the parameter whether patients conceived or not. Data from the sample were subjected to McNemar'stest to determine the significance of the effectiveness of Homoeopathic treatment.

\section{Observation and Results}

\section{Total number of women in the study group $(\mathrm{N})=$ 40}

\section{Relation to age (Table 1)}

In the present study, a total number of 40 infertile women between the ages 18-40 yrs were evaluated. 20 patients were between $18-28$ years and 20 patients were between $29-40$ years.

\section{Degrees of infertility (Figure 1)}

The types of infertility, 33 cases of primary and 7 cases of secondary infertility were included in the study.

Table 1: Relation to age.

\begin{tabular}{|l|l|}
\hline Age Group (Yrs) & No. of Cases \\
\hline $18-28$ & 20 \\
\hline $29-40$ & 20 \\
\hline
\end{tabular}

Table 2: Success Rate According to Causes of Female Infertility.

\begin{tabular}{|c|c|c|c|c|}
\hline Causes & No. of Cases & Conceived & Percentage (\%) & Significance \\
\hline PCOD & 20 & 17 & 85 & $P=0.001 \mathrm{HS}$ \\
\hline Chronic PID & 10 & 7 & 70 & $P=0.002 \mathrm{HS}$ \\
\hline Endometriosis & 10 & 3 & 30 & $P=0.206 \mathrm{NS}$ \\
\hline
\end{tabular}


Case distribution according to causes of infertility (Figure 2)

\section{Success rate according to causes of female infertility (Table 2)}

The above observational findings and values of 40 patients were statistically analyzed for effectiveness of Homoeopathic remedies. Out of 20 cases of PCOD there was $85 \%$ success. In chronic PID, $70 \%$ were successfully treated. Data from the sample were subjected to McNemar's test to determine the significance of the effectiveness of Homoeopathic treatment. ' $p$ ' value in PCOD and Chronic PID were found to be 0.001 and 0.002 respectively, that were highly significant. ' $p$ ' value in Endometriosis was 0.206, that was not significant. This statistical tool was used to see whether there was

\section{Types of Infertility}

35

30

25

20

15

10

0

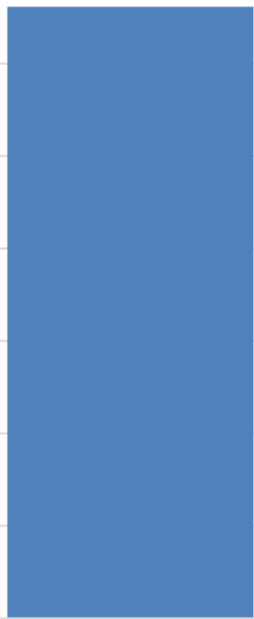

Primary

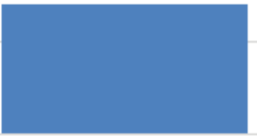

Secondary

Types of Infertility

Figure 1: Degrees of infertility.

\section{Causes of Infertility}

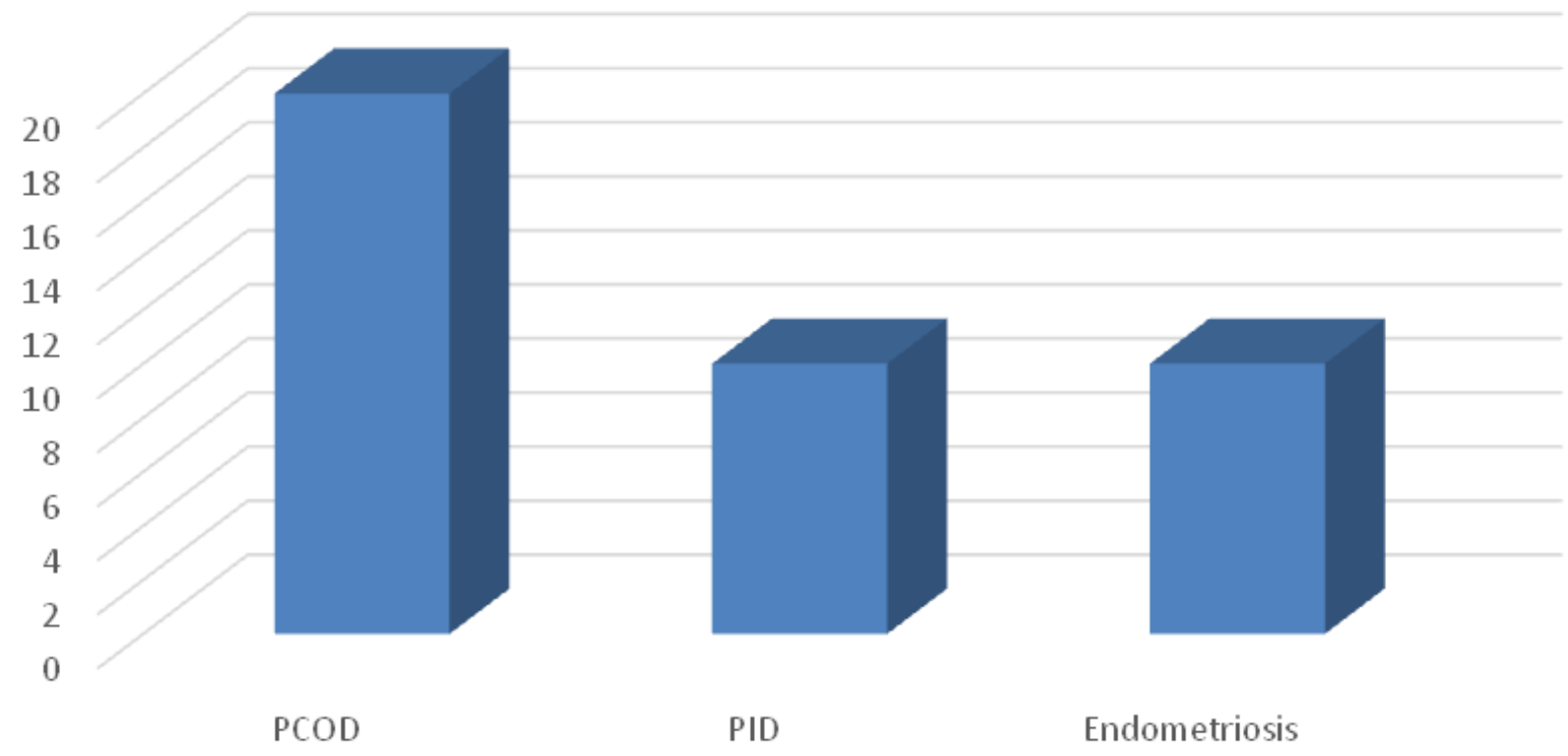

- Causes of Infertility

Figure 2: Case distribution according to causes of infertility. 


\section{Success rate as per causes of female infertility}

25

20

15

10

5

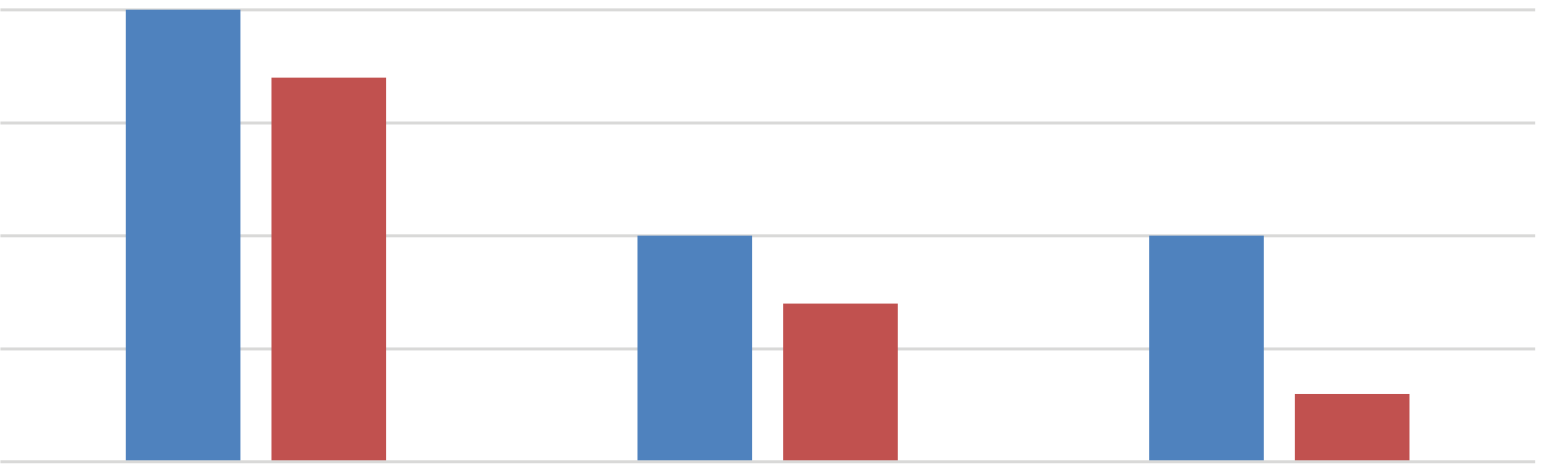

PCOD

PID

Endrometriosis

- Total Cases $\quad$ Conceived

Figure 3: Success rate as per causes of female infertility.

\section{Remedy profile}

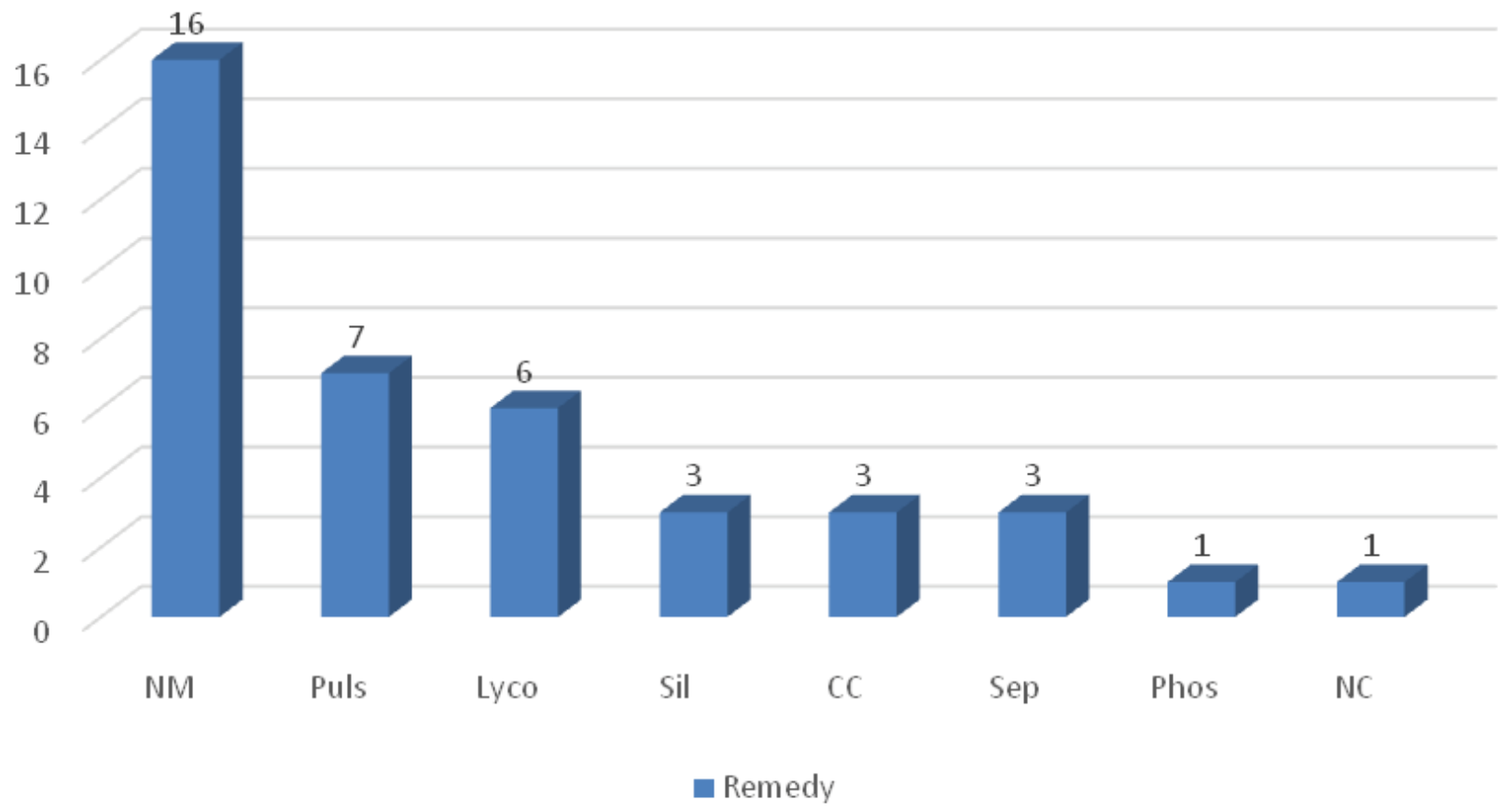

Figure 4: Remedy profile.

significant difference or no difference before and after treatment.

In Endometriosis, the success was only 30\%which was seen in mild endometriosis (Figure 3).

\section{Remedy profile}

The remedies given were Natrum Mur in 16 patients, Pulsatilla in 7 patients, Lycopodium in 6 patients, Silicea in 3 patients, Calcarea Carb in 3 patients, Sepia in 3 patients, Phosphorous in 1 patient and Natrum carb in 1 patient. The remedy was chosen according to the principles and practices of homoeopathy and given on the basis of constitutional totality after detailed case taking recording interpretation and evaluation of symptoms and when required repertorisation (Figure 4).

\section{Discussion}

Infertility is a major health issue challenging the global mass. Conventional medicine is not capable of treating all cases and many times despite the investi- 
gation being normal, the couple fail to conceive. In this scenario homoeopathy has a definite role to play.

The present study shows the effectiveness of Homoeopathic treatment by the rate of conception in infertile females. Our study showed $85 \%$ success in PCOD in female infertility, $70 \%$ success in chronic PID in female infertility and $30 \%$ success in Endometriosis in female infertility. The positive results in different cases of infertility are clinically significant findings. This confirms the efficacy of constitutional Homoeopathic remedies in the treatment of Female Infertility. This study will help to avoid the side-effects of hormonal tablets, unnecessary operations and expensive and uncertain therapeutic measures thus improving the quality of life and chances of conception $[5,6]$.

\section{Conclusion}

The above study has revealed the effectiveness of Homoeopathic treatment in the management of female infertility by the highly significant positive outcome results of conception in infertile females. The well indicated constitutional remedy given on the basis of symptoms' similarity has helped the patients to conceive. This is evident in the positive results obtained in the cases of female infertility due to PCOD, Chronic PID and Endometriosis. Out of 40 cases of female infertility, 27 female patients (67.5\%) conceived after individualized Homoeopathic treatment. Thus Homoeopathic treatment for female infertility has been scientifically validated and emerges as a promising alternative treatment for infertility in women.

\section{References}

1. Jeffcoate (2008) Principles of gynaecology. ( $7^{\text {th }}$ edn), Jaypee Brothers Medical Publishers.

2. Moreira S, Soares E, Tomaz G, Maranhao T, Azevedo G (2010) Polycystic ovary syndrome: A psychosocial approach. Acta Med Port 23: 237-242.

3. Howkins, Bourne (2008) Shaw's text book of gynaecology. (14 ${ }^{\text {th }}$ edn), Elsevier.

4. Wienhard J Tinneberg HR (2003) Alternative treatment possibilities of complaints due to endometriosis. Zentralbl Gynakol 125: 286-289.

5. Kaplan B (1994) Homoeopathy: 2. In pregnancy and for the under-fives. Prof Care Mother Child 4: 185-187.

6. Beal MW (1998) Women's use of complementary and alternative therapies in reproductive health care. J Nurse Midwifery 43: 224-234. 